\title{
Associations of Serum Magnesium with Brain Morphology and Subclinical Cerebrovascular Disease: The Atherosclerosis Risk in Communities-Neurocognitive Study
}

\author{
Aniqa B. Alam ${ }^{1, *}$, DaNashia S. Thomas ${ }^{2}$, Pamela L. Lutsey ${ }^{3} \mathbb{D}$, Srishti Shrestha ${ }^{4}$ and Alvaro Alonso ${ }^{1}$ (D) \\ 1 Department of Epidemiology, Emory University School of Public Health, Atlanta, GA 30322, USA; \\ alvaro.alonso@emory.edu \\ 2 Department of Psychology, School of Arts and Sciences, Clark Atlanta University, Atlanta, GA 30314, USA; \\ danashiathomas@gmail.com \\ 3 Division of Epidemiology and Community Health, University of Minnesota School of Public Health, \\ Minneapolis, MN 55454, USA; lutsey@umn.edu \\ 4 Department of Neurology and the MIND Center, University of Mississippi Medical Center, \\ Jackson, MS 39216, USA; sshrestha1@umc.edu \\ * Correspondence: abalam@emory.edu
}

Citation: Alam, A.B.; Thomas, D.S.; Lutsey, P.L.; Shrestha, S.; Alonso, A. Associations of Serum Magnesium with Brain Morphology and Subclinical Cerebrovascular Disease: The Atherosclerosis Risk in Communities-Neurocognitive Study. Nutrients 2021, 13, 4496. https:// doi.org/10.3390/nu13124496

Academic Editors: Ligia

J. Dominguez, Nicola Veronese and Mario Barbagallo

Received: 11 November 2021 Accepted: 8 December 2021

Published: 16 December 2021

Publisher's Note: MDPI stays neutral with regard to jurisdictional claims in published maps and institutional affiliations.

Copyright: (c) 2021 by the authors. Licensee MDPI, Basel, Switzerland. This article is an open access article distributed under the terms and conditions of the Creative Commons Attribution (CC BY) license (https:/ / creativecommons.org/licenses/by/ $4.0 /)$.
Abstract: Circulating magnesium has been associated with a lower risk of dementia, but the physiologic effects by which magnesium may prevent neurological insults remain unclear. We studied 1466 individuals (mean age $76.2 \pm 5.3,28.8 \%$ black, $60.1 \%$ female) free of prevalent stroke, with measured serum magnesium and with available MRI scans obtained in 2011-2013, participating in the Atherosclerosis Risk in Communities Neurocognitive Study (ARIC-NCS). Cross-sectional differences in frontal, temporal, parietal, and occipital lobe volume, along with deep grey matter, total brain, and white matter hyperintensity volume across serum magnesium (categorized into quintiles and per standard deviation increases) were assessed using multiple linear regression. We also examined associations of magnesium with the prevalence of cortical, subcortical, and lacunar infarcts using multiple logistic regression. After adjusting for demographics, biomarkers, medications, and cardiometabolic risk factors, higher circulating magnesium was associated with greater total brain volume and frontal, temporal, and parietal lobe volumes (volumes 0.14 to 0.19 standard deviations higher comparing Q5 to Q1). Elevated magnesium was also associated with lower odds of subcortical infarcts (OR (95\%CI): $0.44(0.25,0.77)$ comparing Q5 to Q1) and lacunar infarcts (OR (95\%CI): 0.40 $(0.22,0.71)$ comparing Q5 to Q1). Elevated serum magnesium was cross-sectionally associated with greater brain volumes and lower odds of subclinical cerebrovascular disease, suggesting beneficial effects on pathways related to neurodegeneration and cerebrovascular damage. Further exploration through prospective analyses is needed to assess increasing circulating magnesium as a potential neuroprotective intervention.

Keywords: magnesium; brain volume; cerebrovascular disease

\section{Introduction}

Magnesium serves multiple functions in the body, including involvement in cognition. The mineral has been associated with lower risk of dementia in community-based studies [1,2] and has shown neuroprotective effects in animal models of dementia [3,4], but the exact mechanisms through which magnesium may prevent neurological insults remain unclear.

Magnesium deficiency has been linked with increased risk of hypertension [5], cardiovascular diseases [6], and thrombosis [7], which are established risk factors for dementia [8]. The cutoff for hypomagnesemia varies across the literature, but typically ranges from $0.60 \mathrm{mmol} / \mathrm{L}$ to $0.66 \mathrm{mmol} / \mathrm{L}[9,10]$. Magnesium promotes the synthesis of nitric oxide, 
which itself is protective against thrombosis and hypertension due to its anti-platelet properties and ability to induce vasodilation [11]. Magnesium is also a natural antagonist to calcium, which has been known to encourage the over-excitation-and subsequent death-of neurons [12], making it important within the context of dementia. Elevated serum magnesium is associated with a lower risk of cardioembolic stroke [13] and a lower risk of death in patients with acute ischemic stroke [14]. Conversely, lower magnesium can predict ischemic stroke events and the need for carotid revascularization in patients with severe atherosclerosis [15].

Evaluating the association of circulating magnesium with brain imaging markers of neurodegeneration and cerebrovascular disease may offer a clearer picture on the underlying mechanisms linking magnesium and dementia. Thus, we analyzed data from 1466 participants in the Atherosclerosis Risk in Communities (ARIC)-Neurocognitive Study (ARIC-NCS) with available data on circulating magnesium and brain imaging to determine the association of magnesium with brain volumes, infarcts, and white matter disease.

\section{Materials and Methods}

\subsection{Study Population}

The ARIC study is an ongoing prospective cohort of 15,792 participants from 4 communities across the US: Jackson, Mississippi; Washington County, Maryland; Forsyth County, North Carolina; and selected suburbs of Minneapolis, Minnesota. The baseline visit took place from 1987 to 1989. Details of the ARIC cohort have been published elsewhere [16]. As part of ARIC-NCS, an ancillary study to ARIC in visit 5 (2011-2013), participants were invited to undergo in-person neurocognitive examinations, administered by a trained nurse. Those who were found to have cognitive impairments, as well as a subset of cognitively normal participants, were invited to undergo further assessment and a brain MRI [17]. Participants at each visit provided written informed consent. The institutional reviews boards at each participating center approved of the ARIC study protocol. The Institutional Review Board of Emory University approved the present study (IRB00088867, initial approval date 2 August 2016).

From 6538 participants in ARIC visit 5, we included those with available serum magnesium measurements and participation in the MRI study $(n=1577)$. Those with prevalent stroke were excluded from analysis $(n=101)$. Due to low counts, Asian and Native American participants $(n=5)$ and black participants from Washington County $(n=5)$ were excluded. After applying our inclusion and exclusion criteria, 1466 participants were included in the analysis (Figure 1).

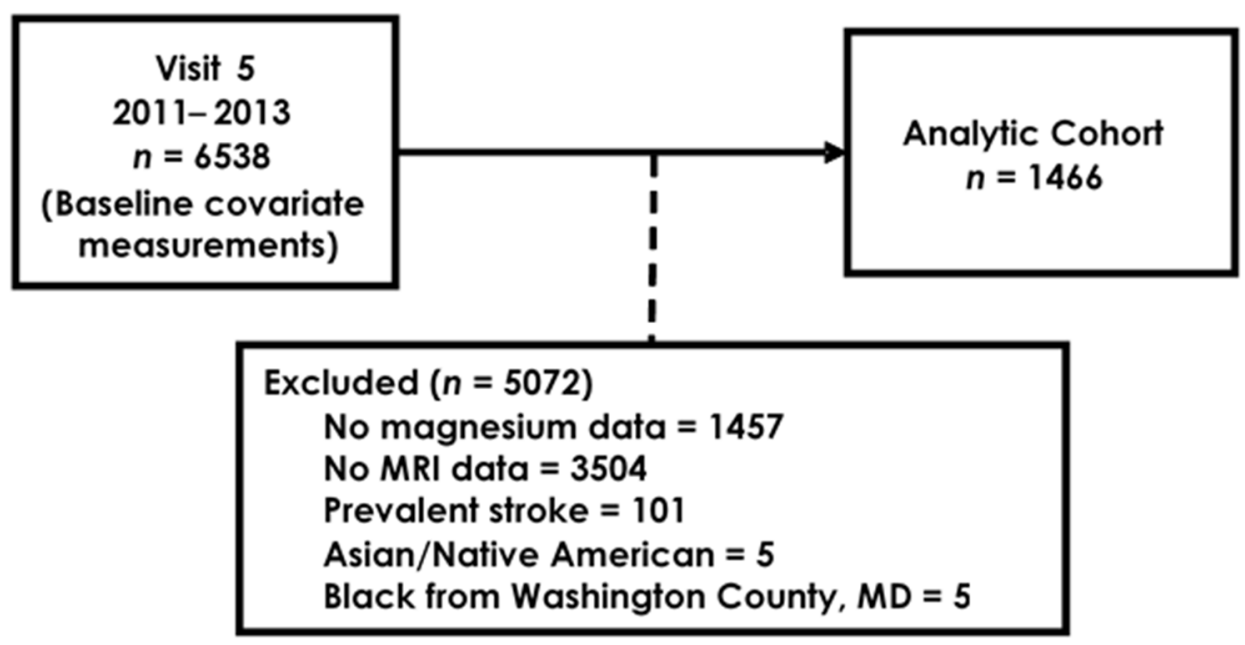

Figure 1. Flow diagram of ARIC participant selection into study. 


\subsection{Brain Imaging}

Imaging protocols have been described at length elsewhere [18]. Briefly, brain volumes were estimated from T1-weighted MP-RAGE sequences using the FreeSurfer system (FreeSurfer, http:/ / surfer.nmr.mgh.harvard.edu, last accessed 9 December 2021) [19]. Infarcts and white matter hyperintensity $(\mathrm{WMH})$ volumes were derived from T2-weighted fluid attenuation inversion recovery (FLAIR) sequences. Lobe volumes of interest included the frontal, temporal, parietal and occipital lobes, along with deep grey matter and total brain volume. Cerebrovascular disease was characterized by the presence of cortical or subcortical infarcts; subcortical infarcts were further classified as lacunar infarcts if they measured $\leq 20 \mathrm{~mm}$ and were located in the caudate, lenticular nucleus, internal capsule, thalamus, brainstem, deep cerebellar white matter, centrum semiovale, or corona radiate [20].

\subsection{Serum Magnesium}

Blood was drawn into vacuum tubes, stored at $-80{ }^{\circ} \mathrm{C}$ and later sent to the ARIC central laboratories. Serum magnesium was measured using the xylidyl blue-I method with a Roche COBAS 6000 chemistry analyzer (Roche Diagnostics, Indianapolis, IN, USA) [21]. Measurements from 242 duplicate samples returned a coefficient of variation of $1.9 \%$.

\subsection{Covariates}

All covariates of interest were measured at visit 5 , except for education, which was recorded at baseline. Education was defined as either "less than high school" or "high school and above". Sodium, potassium, calcium, estimated glomerular filtration rate, c-reactive protein and HDL and total cholesterol were measured in fasting blood samples taken at visit 5 . We accounted for sodium and potassium as these minerals work alongside magnesium and calcium to regulate NMDA receptor functioning [22,23]. Current smoking status was determined through self-report. Body mass index (BMI) was measured during the in-person assessments for visit 5 . Use of hypertension medication was determined at the in-person assessments where participants were asked to bring in their prescription medication. Blood pressure was measured three times in person and the mean of the second and third measurements was used to define hypertension (systolic blood pressure $\geq 140 \mathrm{mmHg}$ or diastolic blood pressure $\geq 90 \mathrm{mmHg}$ or currently taking antihypertensive medication). Diabetes status was based on having a fasting glucose of $126 \mathrm{mg} / \mathrm{dL}$ or greater, a non-fasting glucose of $200 \mathrm{mg} / \mathrm{dL}$ or greater, using medications for diabetes or self-report of diabetes by a physician. Prevalent coronary heart disease (CHD) was defined as having been hospitalized for myocardial infarction (MI), having an MI as determined by ECG, fatal CHD or having a cardiac procedure prior to visit 5 . Prevalent heart failure (HF) was defined using self-reported information collected at the baseline visit and from adjudicated events during follow-up. Participants also provided consent for the genotyping of the APOE gene.

\subsection{Statistical Analysis}

We used multiple linear regression to examine the association of serum magnesium (in approximate quintiles and 1-standard deviation increases) with brain volumes, including the frontal, temporal, parietal and occipital lobes, along with deep grey matter and total brain volume. Each brain volume was scaled using its standard deviation to make easier comparison of associations across different brain regions. We used logistic regression to examine associations of magnesium with markers of subclinical cerebrovascular disease, characterized by the presence of cortical, subcortical, and lacunar infarcts. We also assessed the association of magnesium with log-transformed WMH volumes.

Model 1 adjusted for age at visit 5, race-center (Forsyth/White, Forsyth/Black, Minneapolis/White, Washington/White, Jackson/Black), sex, education and, for the analyses of brain and WMH volumes, estimated total intracranial volume. Model 2 was further adjusted for calcium, sodium, potassium, BMI, HDL and LDL cholesterol, smoking status, 
hypertension, hypertension medication use, estimated glomerular filtration rate, c-reactive protein, diabetes, prevalent $\mathrm{CHD}$, and prevalent $\mathrm{HF}$, along with the presence of the $A P O E$ $\varepsilon 4$ allele. We applied sampling weights that were standardized to visit 5 attendance and also account for selection for brain MRI.

\section{Results}

The 1466 participants included in this analysis had a mean age of 76.2 years (SD: 5.3), were $28.8 \%$ black and $60.1 \%$ female. Those with higher serum magnesium were more educated, more likely to be white and less likely to suffer from hypertension and diabetes (Table 1). It is also worth noting that most participants included are above normal BMI $(\mathrm{BMI} \geq 25)$.

Table 1. Participant characteristics by magnesium quintiles, ARIC-NCS 2011-2013.

\begin{tabular}{|c|c|c|c|c|c|}
\hline & Q1 & Q2 & Q3 & Q4 & Q5 \\
\hline Magnesium, mmol/L & $<0.76$ & $0.76-0.80$ & $0.81-0.84$ & $0.85-0.88$ & $>0.88$ \\
\hline $\mathrm{N}$ & 277 & 226 & 296 & 351 & 316 \\
\hline Age, years & $75.3(5.1)$ & $76.9(5.1)$ & $76.0(5.5)$ & $76.1(5.0)$ & $76.7(5.5)$ \\
\hline Female, \% & 71.1 & 58.4 & 56.1 & 55.3 & 60.8 \\
\hline Black, $\%$ & 39.0 & 36.3 & 28.7 & 23.9 & 19.9 \\
\hline More than high school, \% & 38.3 & 42.9 & 44.3 & 45.3 & 46.5 \\
\hline HDL cholesterol, mg/dL & $51.3(14.7)$ & $52.8(13.4)$ & $53.6(14.1)$ & $52.8(13.7)$ & $53.5(14.5)$ \\
\hline Total cholesterol, mg/dL & $174.9(42.0)$ & $176.0(38.5)$ & $184.3(42.5)$ & $184.3(42.4)$ & $188.2(41.7)$ \\
\hline BMI, $\mathrm{kg} / \mathrm{m}^{2}$ & $30.3(6.3)$ & $29.1(6.0)$ & $28.2(5.6)$ & $27.6(4.8)$ & $27.3(5.0)$ \\
\hline Sodium, mmol/L & $138.3(3.2)$ & $138.9(2.8)$ & $139.1(2.6)$ & $139.1(2.4)$ & $139.6(2.5)$ \\
\hline Potassium, mmol/L & $4.0(0.4)$ & $4.0(0.3)$ & $4.0(0.3)$ & $4.1(0.3)$ & $4.1(0.4)$ \\
\hline Calcium, mg/dL & $9.5(0.4)$ & $9.4(0.3)$ & $9.3(0.4)$ & $9.4(0.4)$ & $9.4(0.4)$ \\
\hline Current smoking, \% & 7.2 & 5.8 & 4.7 & 4.3 & 4.1 \\
\hline Hypertension, \% & 87.7 & 82.7 & 72.3 & 67.0 & 63.9 \\
\hline Hypertension medication, $\%$ & 81.2 & 77.4 & 63.5 & 59.0 & 55.1 \\
\hline Diabetes, $\%$ & 56.0 & 34.5 & 26.7 & 27.4 & 19.9 \\
\hline Coronary heart disease, $\%$ & 7.6 & 12.0 & 8.1 & 8.0 & 10.1 \\
\hline Heart failure, $\%$ & 9.8 & 14.2 & 9.8 & 6.3 & 8.9 \\
\hline $\mathrm{eGFR}, \mathrm{mL} / \mathrm{min} / 1.73 \mathrm{~m}^{2}$ & $66.1(19.3)$ & $66.0(17.4)$ & $67.8(17.7)$ & $67.4(16.5)$ & $62.9(17.7)$ \\
\hline C-reactive protein, $\mathrm{mg} / \mathrm{L}$ & $4.7(8.1)$ & $3.9(6.7)$ & $3.8(5.4)$ & $3.4(4.9)$ & $3.4(6.5)$ \\
\hline APOE $\varepsilon 4$ allele, $\%$ & 26.4 & 31.0 & 30.1 & 29.6 & 28.5 \\
\hline \multicolumn{6}{|c|}{ Markers of subclinical cerebrovascular disease } \\
\hline Cortical infarcts, $\%$ & 9.8 & 10.2 & 8.8 & 9.4 & 7.3 \\
\hline Subcortical infarcts, $\%$ & 21.7 & 20.4 & 15.2 & 16.2 & 13.6 \\
\hline Lacunar infarcts, $\%$ & 21.3 & 19.5 & 15.2 & 16.0 & 12.7 \\
\hline $\begin{array}{l}\text { White matter hyperintensity } \\
\text { volume }\left(\mathrm{cm}^{3}\right),(\mathrm{SD})\end{array}$ & $17(17)$ & $19(18)$ & $16(16)$ & $17(16)$ & $19(20)$ \\
\hline \multicolumn{6}{|c|}{ Brain volume $\left(\mathrm{cm}^{3}\right),(\mathrm{SD})$} \\
\hline Total brain & $983(101)$ & 1007 (106) & 1024 (107) & $1020(99)$ & $1019(118)$ \\
\hline Frontal & $145(15)$ & $149(16)$ & $153(15)$ & $151(14)$ & $151(17)$ \\
\hline Temporal & $99(10)$ & $101(12)$ & $103(11)$ & $103(11)$ & $102(13)$ \\
\hline Occipital & $39(5)$ & $40(6)$ & $41(5)$ & $41(5)$ & $41(6)$ \\
\hline Parietal & $102(12)$ & $105(12)$ & $107(12)$ & $107(12)$ & $107(14)$ \\
\hline Deep grey matter & $42(4)$ & $42(4)$ & $43(4)$ & $43(4)$ & $43(5)$ \\
\hline
\end{tabular}

Values correspond to means (SD) or percentage.

Elevated serum magnesium was associated with greater total brain volume and greater volumes for most lobes at visit 5 , with some evidence of a linear association (Table 2), in both the minimally and fully adjusted models. After adjustment for model 2 covariates, 1-standard deviation $(0.08 \mathrm{mmol} / \mathrm{L})$ higher serum magnesium was associated with 0.03 (occipital lobe volume) to 0.06 (total brain and parietal lobe volumes) higher volumes (in standard deviation units) (Supplemental Figure S1). Further examination of sex and race interactions with magnesium found no consistent differences in these associations of magnesium with brain volumes across these groups, except in the parietal lobe for sex $(p=0.03$, stronger association in males than females) (Supplemental Table S1) and in the frontal lobe for race ( $p=0.02$, stronger association in Black participants) (Supplemental Table S2). 
Table 2. Associations of serum magnesium with brain volumes, ARIC-NCS 2011-2013.

\begin{tabular}{|c|c|c|c|c|c|c|}
\hline & Q1 & Q2 & Q3 & Q4 & Q5 & 1-SD Mg \\
\hline \multicolumn{7}{|c|}{ Total brain volume } \\
\hline Model $1 *$ & Ref. & $0.11(0.02,0.20)$ & $0.19(0.10,0.28)$ & $0.15(0.06,0.23)$ & $0.21(0.12,0.30)$ & $0.06(0.04,0.09)$ \\
\hline Model $2 * *$ & Ref. & $0.09(0.00,0.18)$ & $0.17(0.08,0.26)$ & $0.13(0.05,0.22)$ & $0.19(0.10,0.28)$ & $0.06(0.03,0.09)$ \\
\hline \multicolumn{7}{|l|}{ Frontal lobe } \\
\hline Model 1* & Ref. & $0.08(-0.04,0.19)$ & $0.21(0.11,0.32)$ & $0.11(0.01,0.21)$ & $0.19(0.08,0.29)$ & $0.06(0.02,0.09)$ \\
\hline Model $2 * *$ & Ref. & $0.07(-0.05,0.18)$ & $0.19(0.08,0.30)$ & $0.09(-0.02,0.19)$ & $0.16(0.05,0.27)$ & $0.05(0.01,0.08)$ \\
\hline \multicolumn{7}{|c|}{ Temporal lobe } \\
\hline Model 1* & Ref. & $0.10(0.00,0.23)$ & $0.10(-0.01,0.20)$ & $0.10(0.04,0.20)$ & $0.15(0.05,0.25)$ & $0.06(0.02,0.09)$ \\
\hline Model $2^{* *}$ & Ref. & $0.11(0.00,0.22)$ & $0.09(-0.02,0.20)$ & $0.08(-0.02,0.19)$ & $0.14(0.03,0.24)$ & $0.05(0.02,0.09)$ \\
\hline \multicolumn{7}{|c|}{ Occipital lobe } \\
\hline Model $1 *$ & Ref. & $0.14(0.01,0.28)$ & $0.15(0.02,0.28)$ & $0.15(0.03,0.27)$ & $0.14(0.02,0.26)$ & $0.05(0.01,0.09)$ \\
\hline Model $2 * *$ & Ref. & $0.12(-0.02,0.26)$ & $0.10(-0.03,0.23)$ & $0.11(-0.02,0.23)$ & $0.08(-0.05,0.21)$ & $0.03(-0.01,0.08)$ \\
\hline \multicolumn{7}{|l|}{ Parietal lobe } \\
\hline Model 1* & Ref. & $0.14(0.03,0.25)$ & $0.16(0.05,0.27)$ & $0.13(0.03,0.23)$ & $0.18(0.08,0.29)$ & $0.06(0.03,0.10)$ \\
\hline Model 2 ** & Ref. & $0.13(0.02,0.25)$ & $0.14(0.04,0.25)$ & $0.12(0.02,0.23)$ & $0.17(0.06,0.28)$ & $0.06(0.03,0.10)$ \\
\hline \multicolumn{7}{|c|}{ Deep grey matter } \\
\hline Model 1* & Ref. & $0.08(-0.05,0.21)$ & $0.09(-0.02,0.21)$ & $0.12(0.00,0.23)$ & $0.14(0.01,0.27)$ & $0.05(0.00,0.09)$ \\
\hline Model $2 * *$ & Ref. & $0.06(-0.07,0.19)$ & $0.08(-0.04,0.20)$ & $0.11(-0.01,0.23)$ & $0.13(0.00,0.26)$ & $0.05(0.00,0.09)$ \\
\hline
\end{tabular}

Brain volumes modeled in standard deviation units. ${ }^{*}$ Model 1 results from multiple linear regression adjusted for age, sex, race/center, education and total intracranial volume. 1-SD Mg: $0.08 \mathrm{mmol} / \mathrm{L} .{ }^{* *}$ Model 2 results from multiple linear regression adjusted for model 1, plus LDL and HDL cholesterol, body-mass index, sodium, potassium, calcium, smoking status, hypertension, hypertension medication use, history of coronary heart disease and heart failure, diabetes, eGFR, c-reactive protein, APOE allele. 1-SD Mg: 0.08 mmol/L.

Elevated magnesium was associated with lower odds of subcortical infarcts (OR: 0.44, 95\%CI: 0.25, 0.77 comparing Q5 to Q1, OR: 0.77, 95\%CI: 0.65, 0.91 per 1-standard deviation increase) and lacunar infarcts (OR: 0.40, 95\%CI: 0.22, 0.71 comparing Q5 to Q1; OR: 0.76, 95\%CI: 0.64, 0.89 per 1-standard deviation increase) (Table 3). In contrast, circulating magnesium was not associated with cortical infarctions and WMH volumes. Furthermore, no differences were detected across sex and race, as evidenced by nonsignificant interaction terms (Supplemental Tables S3 and S4, Supplemental Figures S2 and S3).

Table 3. Associations of serum magnesium with markers of cerebrovascular disease, ARIC-NCS 2011-2013.

\begin{tabular}{|c|c|c|c|c|c|c|}
\hline Variable & Q1 & Q2 & Q3 & Q4 & Q5 & 1-SD Mg \\
\hline & \multicolumn{6}{|c|}{ Odds Ratios $(95 \% \mathrm{CI})$} \\
\hline Model $1 *$ & 1 (ref.) & $1.19(0.60,2.35)$ & $1.13(0.59,2.18)$ & $1.03(0.55,1.92)$ & $0.84(0.43,1.65)$ & $1.02(0.84,1.24)$ \\
\hline Model 2 ** & 1 (ref.) & $1.24(0.61,2.53)$ & $1.25(0.63,2.49)$ & $1.22(0.62,2.41)$ & $1.01(0.49,2.07)$ & $1.11(0.90,1.37)$ \\
\hline \multicolumn{7}{|l|}{$\begin{array}{l}\text { Subcortical } \\
\text { infarcts }\end{array}$} \\
\hline Model 1* & 1 (ref.) & $0.89(0.52,1.51)$ & $0.47(0.28,0.78)$ & $0.56(0.34,0.92)$ & $0.42(0.25,0.70)$ & $0.75(0.65,0.88)$ \\
\hline $\begin{array}{l}\text { Model } 2 * * \\
\text { Lacunar } \\
\text { infarcts }\end{array}$ & 1 (ref.) & $0.97(0.56,1.68)$ & $0.52(0.30,0.90)$ & $0.58(0.34,0.99)$ & $0.44(0.25,0.77)$ & $0.77(0.65,0.91)$ \\
\hline Model $1 *$ & 1 (ref.) & $0.86(0.51,1.48)$ & $0.47(0.28,0.78)$ & $0.55(0.33,0.91)$ & $0.38(0.22,0.65)$ & $0.74(0.64,0.86)$ \\
\hline Model $2 * *$ & 1 (ref.) & $0.94(0.54,1.64)$ & $0.52(0.30,0.90)$ & $\begin{array}{l}0.57(0.34,0.98) \\
\text { eta }(95 \% \mathrm{CI})\end{array}$ & $0.40(0.22,0.71)$ & $0.76(0.64,0.89)$ \\
\hline $\begin{array}{l}\text { Ln }(\mathrm{WMH} \\
\text { volume })^{+}\end{array}$ & \multicolumn{6}{|c|}{ Beta $(95 \% \mathrm{CI})$} \\
\hline Model 1 * & Ref. & $-0.01(-0.13,0.16)$ & $-0.15(-0.32,-0.01)$ & $-0.16(-0.32,0.00)$ & $-0.12(-0.26,0.02)$ & $-0.05(-0.10,-0.01)$ \\
\hline Model $2 * *$ & Ref. & $0.03(-0.13,0.18)$ & $-0.10(-0.25,0.04)$ & $-0.11(-0.27,0.05)$ & $-0.07(-0.22,0.08)$ & $-0.03(-0.08,0.02)$ \\
\hline
\end{tabular}

Results from logistic regression (infarcts) and linear regression (WMH volume) adjusted for: * Model 1: age, sex, race/center, and education. 1-SD Mg: $0.08 \mathrm{mmol} / \mathrm{L} .{ }^{* *}$ Model 2: model 1, plus LDL and HDL cholesterol, body-mass index, sodium, potassium, calcium, smoking status, hypertension, hypertension medication use, history of coronary heart disease and heart failure, diabetes, eGFR, c-reactive protein, APOE allele. 1-SD Mg: $0.08 \mathrm{mmol} / \mathrm{L} .{ }^{+}$Additionally adjusted for total intracranial volume. WMH: white matter hyperintensities.

\section{Discussion}

Within this community-based cohort, we found cross-sectional associations of elevated serum magnesium with greater total brain volume and the volume of most specific brain lobes. Furthermore, elevated serum magnesium was also associated with lower odds of subcortical and lacunar infarcts. 
Lower circulating magnesium has been associated with higher risk of dementia [1] and stroke [13], but the mechanisms are not exactly known. Memory formation and other learning processes are informed by N-methyl-D-aspartate receptor activity [24], the overexcitation of which can lead to cell death [12]. Magnesium can inhibit these receptors and prevent neurodegeneration [25], which may explain the larger brain volumes in those with the highest levels of magnesium. Moreover, myelin integrity is impaired in dementia [26]. Magnesium deficient rats were found to have thinner myelin sheaths and fewer myelinated axons overall compared to non-deficient rats [27]. In addition, magnesium sulfate has shown to uphold the integrity of the blood brain barrier by preventing the production of cytokines and other markers of oxidative stress [28]. Furthermore, because magnesium is a natural antagonist to calcium and its inflammatory properties [29], higher circulating magnesium may reduce the risk of ischemic stroke [30], and improve endothelial function [31]. These mechanisms, overall, may explain the associations between circulating magnesium and brain volumes in the ARIC cohort.

That said, of all the magnesium in the body, only $0.3 \%$ is in the blood [32]. Magnesium in the body can be primarily found in the bones, soft tissues, and teeth [33]. Though serum magnesium only represents a small portion of the total body magnesium, serum measurements may still have some utility in predicting brain size and health, particularly when considering blood brain barrier (BBB) permeability. The tight junctions of the BBB can be an issue in the transport of micronutrients into the cerebrospinal fluid (CSF) and brain [34]. Yet, low molecular weight magnesium actually has a better chance of passing through this barrier than high molecular weight metals such as iron, copper, and zinc [35], which are involved in the accumulation of amyloid plaques in the brain [36]. In instances of traumatic brain injury, studies have reported decreases in both brain magnesium [37] and serum magnesium [38]. Thus, while the extent to which serum magnesium is correlated with central nervous system magnesium is unknown, there appears to be some degree of positive association.

We did not find a clear relationship of circulating magnesium with WMH volume and the presence of cortical infarcts, but this is also consistent with previous studies. For example, administering magnesium sulfate to hypertensive rats did not appear to affect the infarct volume; interestingly enough, it did appear to attenuate the motor impairments that would accompany such white matter damage [39]. That said, we did find elevated magnesium to have a protective effect against subcortical infarcts. The IMAGES randomized clinical trial yielded similar results in that while intravenous magnesium sulfate given in the setting of acute stroke did not appear to affect outcomes for disability and death globally, there was a significant reduction in poor outcomes for those with non-cortical stroke, particularly those with lacunar clinical syndromes [40].

There are several strengths to our study. To our knowledge, this is the first study to look at the relationship of serum magnesium with brain volumes and subclinical indicators of cerebrovascular disease. Furthermore, we account for a wide array of potential confounders including anthropomorphic measurements, lifestyle factors, biomarkers, medication use, and clinical CVD risk factors. That said, some limitations present in the study warrant a cautious interpretation of our results. First, the study is cross-sectional in nature with one-time measurements of serum magnesium, brain volumes, and brain lesions, making it difficult to parse the directionality of the associations. Second, many participants had died by visit 5 or were alive but refused or were unwilling to attend visits. Thus, participants selected into the study may have suffered less neurodegeneration and damage than those lost to follow-up, which could lead to potential selection bias. Third, despite adjustment for a wide array of covariates, there may be additional factors not accounted for in our models.

\section{Conclusions}

We found elevated serum magnesium to be associated with greater brain volumes and lower odds of subclinical cerebrovascular disease compared to those with low circulating magnesium, potentially implicating protection against neuronal degeneration and 
cerebrovascular disease as mechanisms responsible for the lower risk of dementia in those with higher circulating magnesium. These findings should be confirmed in well-designed prospective analyses, with particular focus on evaluating the potential of interventions aimed at increasing circulating magnesium for the prevention of neurodegeneration and cerebrovascular disease. Given the established effect of oral magnesium supplementation on circulating magnesium concentrations [41], these interventions have the potential to make a significant impact on the prevention of dementia, a major contributor to the burden of disease in the population.

Supplementary Materials: The following are available online at https: / www.mdpi.com/article/ 10.3390/nu13124496/s1, Table S1: Associations of serum magnesium with brain volumes, by sex, ARIC-NCS 2011-2013; Table S2: Associations of serum magnesium with brain volumes, by race, ARIC-NCS 2011-2013; Table S3: Associations of serum magnesium with subclinical cerebrovascular disease, by sex, ARIC-NCS 2011-2013; Table S4: Associations of serum magnesium with subclinical cerebrovascular disease, by race, ARIC-NCS 2011-2013; Figure S1: Forest plot of the association of magnesium with brain volumes in participants at visit 5; Figure S2: Forest plot of the association of magnesium with subclinical cerebrovascular disease in participants at visit 5; Figure S3: Forest plot of the association of magnesium with log-transformed white matter hyperintensity (WMH) volume in participants at visit 5 .

Author Contributions: Conceptualization, A.B.A., D.S.T. and A.A.; methodology, A.B.A., D.S.T., A.A., P.L.L. and S.S.; formal analysis, A.B.A. and A.A.; writing-original draft preparation, A.B.A., D.S.T. and A.A.; writing-review and editing, A.B.A., D.S.T., A.A., P.L.L. and S.S. All authors have read and agreed to the published version of the manuscript.

Funding: The Atherosclerosis Risk in Communities Study is carried out as a collaborative study supported by National Heart, Lung, and Blood Institute contracts (HHSN268201700001I, HHSN268201700002I, HHSN268201700003I, HHSN268201700005I, HHSN268201700004I). Neurocognitive data is collected by U01 2U01HL096812, 2U01HL096814, 2U01HL096899, 2U01HL096902, 2U01HL096917 from the NIH (NHLBI, NINDS, NIA, and NIDCD), and with previous brain MRI examinations funded by R01-HL70825 from the NHLBI. Additional support was provided by National Institutes of Health awards K24HL148521, K24 HL159246, and P30AG066511. The content is solely the responsibility of the authors and does not necessarily represent the official views of the National Institutes of Health.

Institutional Review Board Statement: The study was conducted according to the guidelines of the Declaration of Helsinki, and approved by the Institutional Review Board of each participating ARIC center.

Informed Consent Statement: Written informed consent has been obtained from ARIC participants to publish this paper.

Data Availability Statement: The data presented in this study may be available on request from the corresponding author or through ARIC directly: https://sites.cscc.unc.edu/aric/distributionagreements (last accessed 9 December 2021).

Acknowledgments: The authors thank the staff and participants of the ARIC study for their important contributions.

Conflicts of Interest: The authors declare no conflict of interest.

\section{References}

1. Alam, A.B.; Lutsey, P.L.; Gottesman, R.F.; Tin, A.; Alonso, A. Low Serum Magnesium is Associated with Incident Dementia in the ARIC-NCS Cohort. Nutrients 2020, 12, 3074. [CrossRef] [PubMed]

2. Kieboom, B.C.T.; Licher, S.; Wolters, F.J.; Ikram, M.K.; Hoorn, E.J.; Zietse, R.; Stricker, B.H. Serum magnesium is associated with the risk of dementia. Neurology 2017, 89, 1716-1722. [CrossRef] [PubMed]

3. Li, W.; Yu, J.; Liu, Y.; Huang, X.; Abumaria, N.; Zhu, Y.; Huang, X.; Xiong, W.; Ren, C.; Liu, X.-G.; et al. Elevation of brain magnesium prevents synaptic loss and reverses cognitive deficits in Alzheimer's disease mouse model. Mol. Brain $2014,7,65$. [CrossRef] [PubMed]

4. Huang, Y.; Huang, X.; Zhang, L.; Han, F.; Pang, K.L.; Li, X.; Shen, J.Y. Magnesium boosts the memory restorative effect of environmental enrichment in Alzheimer's disease mice. CNS Neurosci. Ther. 2018, 24, 70-79. [CrossRef] [PubMed]

5. Flink, E.B. Magnesium deficiency. Etiology and clinical spectrum. Acta Med. Scand Suppl. 1981, 647, 125-137. [CrossRef] [PubMed] 
6. Rayssiguier, Y. Role of magnesium and potassium in the pathogenesis of arteriosclerosis. Magnesium 1984, 3, 226-238. [PubMed]

7. Shechter, M.; Merz, C.N.; Rude, R.K.; Paul Labrador, M.J.; Meisel, S.R.; Shah, P.K.; Kaul, S. Low intracellular magnesium levels promote platelet-dependent thrombosis in patients with coronary artery disease. Am. Heart J. 2000, 140, 212-218. [CrossRef]

8. Gottesman, R.F.; Albert, M.S.; Alonso, A.; Coker, L.H.; Coresh, J.; Davis, S.M.; Deal, J.A.; McKhann, G.M.; Mosley, T.H.; Sharrett, A.R.; et al. Associations Between Midlife Vascular Risk Factors and 25-Year Incident Dementia in the Atherosclerosis Risk in Communities (ARIC) Cohort. JAMA Neurol. 2017, 74, 1246-1254. [CrossRef]

9. Gragossian, A.; Bashir, K.; Friede, R. Hypomagnesemia; StatPearls: Treasure Island, FL, USA, 2021.

10. Pham, P.C.; Pham, P.A.; Pham, S.V.; Pham, P.T.; Pham, P.M.; Pham, P.T. Hypomagnesemia: A clinical perspective. Int. J. Nephrol. Renov. Dis. 2014, 7, 219-230. [CrossRef]

11. Maier, J.A.; Bernardini, D.; Rayssiguier, Y.; Mazur, A. High concentrations of magnesium modulate vascular endothelial cell behaviour in vitro. Biochim. Biophys. Acta 2004, 1689, 6-12. [CrossRef] [PubMed]

12. Zipfel, G.J.; Babcock, D.J.; Lee, J.M.; Choi, D.W. Neuronal apoptosis after CNS injury: The roles of glutamate and calcium. J. Neurotrauma 2000, 17, 857-869. [CrossRef]

13. Larsson, S.C.; Traylor, M.; Burgess, S.; Boncoraglio, G.B.; Jern, C.; Michaelsson, K.; Markus, H.; MEGASTROKE Project Of The International Stroke Genetics Consortium. Serum magnesium and calcium levels in relation to ischemic stroke: Mendelian randomization study. Neurology 2019, 92, e944-e950. [CrossRef]

14. Feng, P.; Niu, X.; Hu, J.; Zhou, M.; Liang, H.; Zhang, Y.; Tong, W.; Xu, T. Relationship of serum magnesium concentration to risk of short-term outcome of acute ischemic stroke. Blood Press. 2013, 22, 297-301. [CrossRef] [PubMed]

15. Amighi, J.; Sabeti, S.; Schlager, O.; Mlekusch, W.; Exner, M.; Lalouschek, W.; Ahmadi, R.; Minar, E.; Schillinger, M. Low serum magnesium predicts neurological events in patients with advanced atherosclerosis. Stroke 2004, 35, 22-27. [CrossRef] [PubMed]

16. Wright, J.D.; Folsom, A.R.; Coresh, J.; Sharrett, A.R.; Couper, D.; Wagenknecht, L.E.; Mosley, T.H., Jr.; Ballantyne, C.M.; Boerwinkle, E.A.; Rosamond, W.D.; et al. The ARIC (Atherosclerosis Risk in Communities) Study: JACC Focus Seminar 3/8. J. Am. Coll. Cardiol. 2021, 77, 2939-2959. [CrossRef] [PubMed]

17. Knopman, D.S.; Gottesman, R.F.; Sharrett, A.R.; Wruck, L.M.; Windham, B.G.; Coker, L.; Schneider, A.L.; Hengrui, S.; Alonso, A.; Coresh, J.; et al. Mild Cognitive Impairment and Dementia Prevalence: The Atherosclerosis Risk in Communities Neurocognitive Study (ARIC-NCS). Alzheimers Dement. 2016, 2, 1-11. [CrossRef] [PubMed]

18. Knopman, D.S.; Griswold, M.E.; Lirette, S.T.; Gottesman, R.F.; Kantarci, K.; Sharrett, A.R.; Jack, C.R., Jr.; Graff-Radford, J.; Schneider, A.L.; Windham, B.G.; et al. Vascular imaging abnormalities and cognition: Mediation by cortical volume in nondemented individuals: Atherosclerosis risk in communities-neurocognitive study. Stroke 2015, 46, 433-440. [CrossRef] [PubMed]

19. Fischl, B.; Salat, D.H.; Busa, E.; Albert, M.; Dieterich, M.; Haselgrove, C.; van der Kouwe, A.; Killiany, R.; Kennedy, D.; Klaveness, S.; et al. Whole brain segmentation: Automated labeling of neuroanatomical structures in the human brain. Neuron 2002, 33, 341-355. [CrossRef]

20. Wardlaw, J.M.; Smith, E.; Biessels, G.J.; Cordonnier, C.; Fazekas, F.; Frayne, R.; Lindley, R.; O’Brien, J.; Barkhof, F.; Benavente, O.R.; et al. Neuroimaging standards for research into small vessel disease and its contribution to ageing and neurodegeneration. Lancet Neurol. 2013, 12, 822-838. [CrossRef]

21. Alonso, A.; Rooney, M.R.; Chen, L.Y.; Norby, F.; Saenger, A.K.; Soliman, E.Z.; O’Neal, W.T.; Hootman, K.C.; Selvin, E.; Lutsey, P.L. Circulating electrolytes and the prevalence of atrial fibrillation and supraventricular ectopy: The Atherosclerosis Risk in Communities (ARIC) study. Nutr. Metab. Cardiovasc. Dis. 2020, 30, 1121-1129. [CrossRef] [PubMed]

22. Newcomer, J.W.; Farber, N.B.; Olney, J.W. NMDA receptor function, memory, and brain aging. Dialogues Clin. Neurosci. 2000, 2, 219-232. [PubMed]

23. De Lores Arnaiz, G.R.; Bersier, M.G. Relationship between Na+, K+-ATPase and NMDA receptor at central synapses. Curr. Protein Pept. Sci. 2014, 15, 761-777. [CrossRef] [PubMed]

24. Olivares, D.; KDeshpande, V.; Shi, Y.; KLahiri, D.; HGreig, N.; TRogers, J.; Huang, X. N-methyl D-aspartate (NMDA) receptor antagonists and memantine treatment for Alzheimer's disease, vascular dementia and Parkinson's disease. Curr. Alzheimer Res. 2012, 9, 746-758. [CrossRef]

25. Hynd, M.R.; Scott, H.L.; Dodd, P.R. Glutamate-mediated excitotoxicity and neurodegeneration in Alzheimer's disease. Neurochem. Int. 2004, 45, 583-595. [CrossRef] [PubMed]

26. Suri, S.; Mackay, C.E.; Kelly, M.E.; Germuska, M.; Tunbridge, E.M.; Frisoni, G.B.; Matthews, P.M.; Ebmeier, K.P.; Bulte, D.P.; Filippini, N. Reduced cerebrovascular reactivity in young adults carrying the APOE epsilon4 allele. Alzheimers Dement. 2015, 11, 648-657.e1. [CrossRef] [PubMed]

27. Gong, H.; Takami, Y.; Amemiya, T. Ultrastructure of the optic nerve in magnesium-deficient rats. Ophthalmic Res. 2003, 35, 84-92. [CrossRef] [PubMed]

28. Shadman, J.; Sadeghian, N.; Moradi, A.; Bohlooli, S.; Panahpour, H. Magnesium sulfate protects blood-brain barrier integrity and reduces brain edema after acute ischemic stroke in rats. Metab. Brain Dis. 2019, 34, 1221-1229. [CrossRef] [PubMed]

29. Dalal, P.J.; Muller, W.A.; Sullivan, D.P. Endothelial Cell Calcium Signaling during Barrier Function and Inflammation. Am. J. Pathol. 2020, 190, 535-542. [CrossRef] [PubMed]

30. Adebamowo, S.N.; Jimenez, M.C.; Chiuve, S.E.; Spiegelman, D.; Willett, W.C.; Rexrode, K.M. Plasma magnesium and risk of ischemic stroke among women. Stroke 2014, 45, 2881-2886. [CrossRef] 
31. Shechter, M.; Sharir, M.; Labrador, M.J.; Forrester, J.; Silver, B.; Bairey Merz, C.N. Oral magnesium therapy improves endothelial function in patients with coronary artery disease. Circulation 2000, 102, 2353-2358. [CrossRef]

32. Elin, R.J. Assessment of magnesium status. Clin. Chem. 1987, 33, 1965-1970. [CrossRef] [PubMed]

33. Elin, R.J. Magnesium metabolism in health and disease. Dis. Mon. 1988, 34, 161-218. [CrossRef]

34. Kusuhara, H.; Sugiyama, Y. Efflux transport systems for drugs at the blood-brain barrier and blood-cerebrospinal fluid barrier (Part 1). Drug Discov. Today. 2001, 6, 150-156. [CrossRef]

35. Nischwitz, V.; Berthele, A.; Michalke, B. Speciation analysis of selected metals and determination of their total contents in paired serum and cerebrospinal fluid samples: An approach to investigate the permeability of the human blood-cerebrospinal fluid-barrier. Anal. Chim. Acta. 2008, 627, 258-269. [CrossRef] [PubMed]

36. Bush, A.I. The metallobiology of Alzheimer's disease. Trends Neurosci. 2003, 26, 207-214. [CrossRef]

37. Vink, R.; McIntosh, T.K.; Demediuk, P.; Weiner, M.W.; Faden, A.I. Decline in intracellular free $\mathrm{Mg}^{2+}$ is associated with irreversible tissue injury after brain trauma. J. Biol. Chem. 1988, 263, 757-761. [CrossRef]

38. Nayak, R.; Attry, S.; Ghosh, S.N. Serum Magnesium as a Marker of Neurological Outcome in Severe Traumatic Brain Injury Patients. Asian J. Neurosurg. 2018, 13, 685-688. [CrossRef] [PubMed]

39. Lecrux, C.; McCabe, C.; Weir, C.J.; Gallagher, L.; Mullin, J.; Touzani, O.; Muir, K.W.; Lees, K.R.; Macrae, I.M. Effects of magnesium treatment in a model of internal capsule lesion in spontaneously hypertensive rats. Stroke 2008, 39, 448-454. [CrossRef]

40. Aslanyan, S.; Weir, C.J.; Muir, K.W.; Lees, K.R.; IMAGES Study Investigators. Magnesium for treatment of acute lacunar stroke syndromes: Further analysis of the IMAGES trial. Stroke 2007, 38, 1269-1273. [CrossRef]

41. Lutsey, P.L.; Chen, L.Y.; Eaton, A.; Jaeb, M.; Rudser, K.D.; Neaton, J.D.; Alonso, A. A Pilot Randomized Trial of Oral Magnesium Supplementation on Supraventricular Arrhythmias. Nutrients 2018, 10, 884. [CrossRef] 